\title{
The Clinical and Radiological Characterizations of the Allergic Phenotype of Chronic Rhinosinusitis with Nasal Polyps
}

\author{
This article was published in the following Dove Press journal:
}

Journal of Asthma and Allergy

\author{
Baharudin Abdullah (D) \\ Selvamalar Vengathajalam' \\ Mohd Khairi Md Daud (ID) \\ Zahiruddin Wan Mohammad ${ }^{2}$ \\ Aneeza Hamizan $\left(\mathbb{D}^{3}\right.$ \\ Salina Husain $\mathbb{D D}^{3}$ \\ 'Department of Otorhinolaryngology- \\ Head \& Neck Surgery, School of Medical \\ Sciences, Universiti Sains Malaysia, \\ Kubang Kerian 16150, Kelantan, Malaysia; \\ ${ }^{2}$ Department of Community Medicine, \\ School of Medical Sciences, Universiti \\ Sains Malaysia, Kubang Kerian 16150, \\ Kelantan, Malaysia; ${ }^{3}$ Department of \\ Otorhinolaryngology-Head and Neck \\ Surgery, Faculty of Medicine, Universiti \\ Kebangsaan Malaysia Medical Centre, \\ Kuala Lumpur 56000, Malaysia
}

Purpose: The allergic phenotype of chronic rhinosinusitis (CRS) and central compartment atopic disease (CCAD) have been described. The CCAD is a radiological phenotype in patients with CRS that presents as a central mucosal disease due to allergy. The subset of patients having chronic rhinosinusitis with nasal polyps (CRSwNP) has not been well characterized. We aim to describe the clinical and radiological characterizations of patients presenting with the allergic phenotype of CRSwNP.

Patients and Methods: A cross-sectional study at a tertiary hospital was performed. Adult patients diagnosed with CRSwNP who had both allergology and radiological assessments were enrolled. The symptoms of allergic rhinitis, Lund-Kennedy (LK) endoscopic scoring, Lund-Mackay (LM) computed tomography scan of paranasal sinuses (CTPNS) scoring, CCAD features, skin prick test (SPT) and level of specific IgE were assessed. All the patients underwent SPT for house dust mites.

Results: A total of 38 patients were enrolled. Symptoms, endoscopic and CTPNS scores were higher in the allergy and CCAD groups compared to the nonallergy and nonCCAD groups. The symptom of "need to blow nose" was statistically significant in allergy vs nonallergy ( $p=0.01)$ and CCAD vs nonCCAD $(p=0.02)$. There were significant differences in the endoscopic scores in both allergy and CCAD (allergy vs nonallergy, $p=0.01$; CCAD vs nonCCAD, $p=0.03$ ), and CT scores in both allergy and CCAD (allergy vs nonallergy, $p=0.02$; CCAD vs nonCCAD, $p=0.02$ ). All patients with CCAD have worse scoring than nonCCAD (LK score, $p=0.03$; LM score, $p=0.02$ ). Patients with allergy have more polypoidal involvement of the middle turbinates (left middle turbinate, $p=0.141$; right middle turbinate, $p=0.074$ ) and CCAD (left middle turbinate, $p=0.017$; right middle turbinate, $p=0.009$ ) than nonallergy and nonCCAD patients.

Conclusion: Allergic phenotype of CRSwNP has a worse clinical and radiological disease burden. Optimal treatment of allergy is essential for a better outcome.

Keywords: allergy, atopy, chronic rhinosinusitis, nasal polyps, central compartment atopic disease

\section{Introduction}

The central compartment atopic disease (CCAD), a radiological phenotype in patients with chronic rhinosinusitis (CRS) and atopy, has previously been described. ${ }^{1} \mathrm{CCAD}$ describes the changes due to allergic reaction in the nose causing obstruction involving the middle turbinates, superior turbinates and posterosuperior part of the septum. CCAD was developed to recognize the role of aeroallergen as one of the causes of allergic phenotype of chronic rhinosinusitis. Allergy has been proposed as one of the
Correspondence: Baharudin Abdullah Department of OtorhinolaryngologyHead and Neck Surgery, School of Medical Sciences, Universiti Sains

Malaysia, Kubang Kerian 16150, Kelantan, Malaysia

Tel +6097676416

Fax +6097676424

Email profbaha@gmail.com 
etiological factors in the pathogenesis of nasal polyps but its role in CRS remains unresolved. ${ }^{2,3}$ Most studies used multiple allergens to confirm allergy in CRS patients with nasal polyps (CRSwNP) or without nasal polyps (CRSsNP) that may contribute to the conflicting results. As it is often considered as one disease entity, the same considerations were applied for CRSwNP and CRSsNP. But, CRSwNP should be considered as a distinct entity due to the differences in its inflammatory mediators from CRSsNP. ${ }^{4}$ CRSsNP is a Th1 shifted immune response with predominance of mononuclear cells and interferon gamma in the nasal tissue, whereas CRSwNP is a Th2 dominated disease with predominance of interleukin 5 (IL-5) and eosinophils. ${ }^{5}$ Hence, it is to be expected that their mechanism of response to multiple allergens is variable. Their diverse nature and heterogeneous pathophysiology explain the variation and contradictory results in prior studies.

Previous study that described the allergic phenotype of CRS, grouped CRSwNP and CRSsNP together and used multiple aeroallergens sensitization in their analysis. ${ }^{1} \mathrm{We}$ postulate the outcome is likely to be different if both types are analyzed separately and a standardized aeroallergen is used. With the standardization of the predominant allergen and the type of CRS, a more reliable and predictive response could be elicited. The purpose of our study was to define the clinical and radiological characterizations of the allergic phenotype of CRSwNP in patients with allergy to house dust mites. We chose house dust mites as it is the commonest aeroallergens in our population.

\section{Patients and Methods}

This was a cross-sectional study conducted from June 2018 to June 2019 on patients diagnosed with CRSwNP who had both allergology and radiological assessments. A prior approval from the Human Research Ethics Review Board of Universiti Sains Malaysia (JEPeM Code: USM/JEPeM/ 17,120,676) was obtained and written informed consent was taken from all participants.

\section{Study Population}

Consecutive adult patients above the age of 18 years with the diagnosis of CRSwNP according to the European position paper on rhinosinusitis and nasal polyps guidelines ${ }^{6}$ who had both available allergy testing and radiological examinations were included. Allergic and atopy history such as allergic rhinitis, allergic conjunctivitis, drug allergy, eczema, asthma and perennial allergy were obtained from all patients using a proforma.
Patients who had previous surgery, sinusitis from dental origin, fungal rhinosinusitis, aspirin exacerbated respiratory disease and mucocele were excluded. Demographic data including age, gender, smoking habits, presence of systemic diagnosis in addition to a history of asthma were obtained from patients. The use of intranasal corticosteroid or oral steroid were documented. The symptoms score, Lund-Kennedy (LK) endoscopic scoring, Lund-Mackay (LM) computed tomography scan of paranasal sinuses (CTPNS) scoring, CCAD features, skin prick test (SPT) and level of specific IgE were assessed.

\section{Allergy Status}

Clinical history for allergy and atopy (allergic rhinitis, eczema and asthma) was obtained from all patients prior to SPT. SPT was done on each patient before treatment or two weeks after refraining from oral/intranasal corticosteroid and oral antihistamine. SPT was performed on the patient's volar forearm using the two most common inhalant allergens in our patients, ${ }^{7}$ the Dermatophagoides and Blomia tropicalis. Histamine was used for positive control and saline for negative control. A positive skin test result was defined as a wheal of more than $3 \mathrm{~mm}$ to the house dust mite allergens with a nonreactive negative control after 15 min. Patient with wheal size of less than $3 \mathrm{~mm}$ with positive allergy and atopy history underwent venous blood taking for serum specific IgE level to Dermatophagoides and Blomia tropicalis (analyzed via ImmunoCAP, Phadia AB, Uppsala, Sweden). A value of $0.35 \mathrm{kU} / \mathrm{L}$ or more of the serum specific IgE was considered positive for allergy. Patients with either a positive SPT or serum specific IgE were considered as having allergy.

\section{Symptoms and Endoscopic Assessments}

Three rhinological symptoms (sneezing, runny nose and the need to blow nose) validated in an earlier study ${ }^{1}$ to be representative of allergy was used for assessment of allergy. These symptoms were scored on a scale of 0 to $5(0=$ no problem, $1=$ very mild, $2=$ mild, $3=$ moderate, $4=$ severe and $5=$ worst). Symptoms of CRSwNP such as nasal obstruction, hyposmia, rhinorrhea, postnasal drip, facial fullness or pain and headache were evaluated and total symptoms were scored according to the visual analogue scale from 0 to 10 according to the symptom severity.

LK endoscopic scoring system ${ }^{8}$ was used to evaluate the nasal endoscopic findings. The scoring was as follows: size of polyps $(0=$ none, $1=$ till middle meatus, $2=$ extend beyond middle meatus), edema of the turbinates 
( $0=$ absent, $1=$ mild to moderate edema, $2=$ polypoidal degeneration) and discharge $(0=$ none, $1=$ clear and thin, $2=$ thick and purulent) with a possible total score of 12 .

\section{Radiological Assessment}

The CTPNS was retrieved from the radiology information system (RIS) and picture archive communication system (PACS). The CTPNS images were acquired from SOMATOM ${ }^{\circledR}$ Definition AS+ (Siemens Healthcare $\mathrm{GmbH}$, Germany) which can produce 128 slices of images per rotation. The paranasal sinuses were assessed from serial images ( $1 \mathrm{~mm}$ slices) on coronal, axial, and sagittal views on both right and left side. CTPNS done within three months prior or after allergy assessment was included. The CTPNS images were reviewed and classified according to LM scoring system ${ }^{9}$ by an otorhinolaryngologist (BA) who was blinded to the allergy status. The LM scoring assigns a score of 0,1 , or 2 to each sinus (maxillary, anterior ethmoid, posterior ethmoid, sphenoid and frontal) and a score of 0 or 2 for each ostiomeatal complex for a possible total score of 24. A score of 0 is assigned for a completed aerated sinus, 1 for partially opacified sinus, and a score of 2 is assigned for a completely opacified sinus. In reference to the ostiomeatal complex, 0 is assigned if unobstructed and 2 is assigned if obstruction exists. The CCAD features were classified according to previous works done by DelGaudio et $\mathrm{al}^{10}$ and Hamizan et al. ${ }^{1}$ Centrally limited disease was defined by normal sinus mucosa or mucosal thickening involving the floor and medial wall of the sinus (Figure 1). The diffuse disease was defined as mucosal thickening involving all four walls of the sinus or involving the lateral wall and the roof of the sinus. Patients with centrally limited disease with normal sinus mucosa or mucosal thickening involving the floor and medial wall of the sinus were classified as CCAD while those without these features were classified as nonCCAD.

\section{Statistical Analysis}

Sample size was calculated using Power and Sample Size Program which revealed a total of 38 patients (19 with allergy and 19 without allergy) required for this study to achieve significance (true failure rate of 0.5 , power of 0.8 , type 1 error of 0.05). Data was entered and analyzed using IBM SPSS Statistics for Windows, Version 22.0 (IBM Corp, Armonk, NY, USA). Descriptive statistics was used to summarize the sociodemographic characteristics of subjects, symptoms severity, LK endoscopic and LM CTPNS scoring in CRSwNP. Numerical data presented as

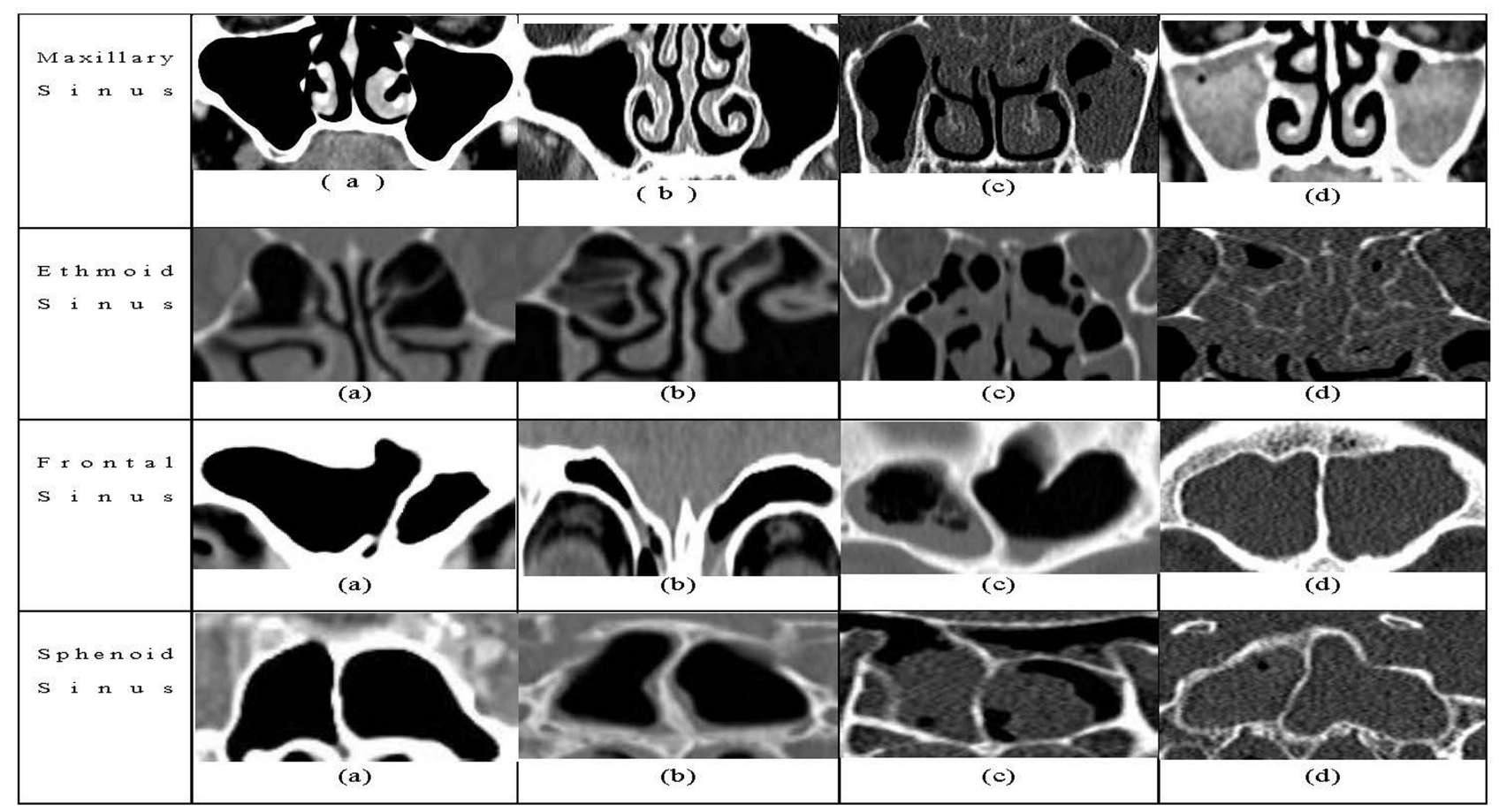

Figure I Central disease with (a) normal sinus mucosa, or (b) mucosal thickening of floor and medial wall. Diffuse disease with (c) mucosal thickening of lateral wall and roof, or (d) involvement of all four walls. Scale bar, $1 \mathrm{~cm}$ is equal to $5 \mathrm{~cm}$. 


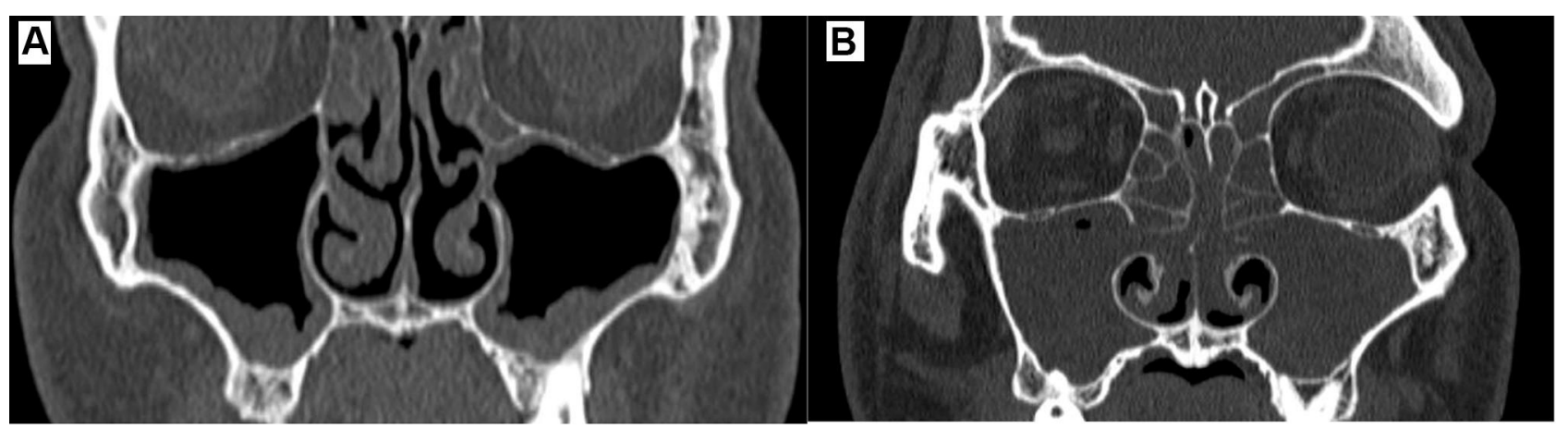

Figure 2 Comparison of maxillary sinus CCAD (A) vs nonCCAD (B) features. Scale bar, $1 \mathrm{~cm}$ is equal to $5 \mathrm{~cm}$. Abbreviation: CCAD, central compartment atopic disease.
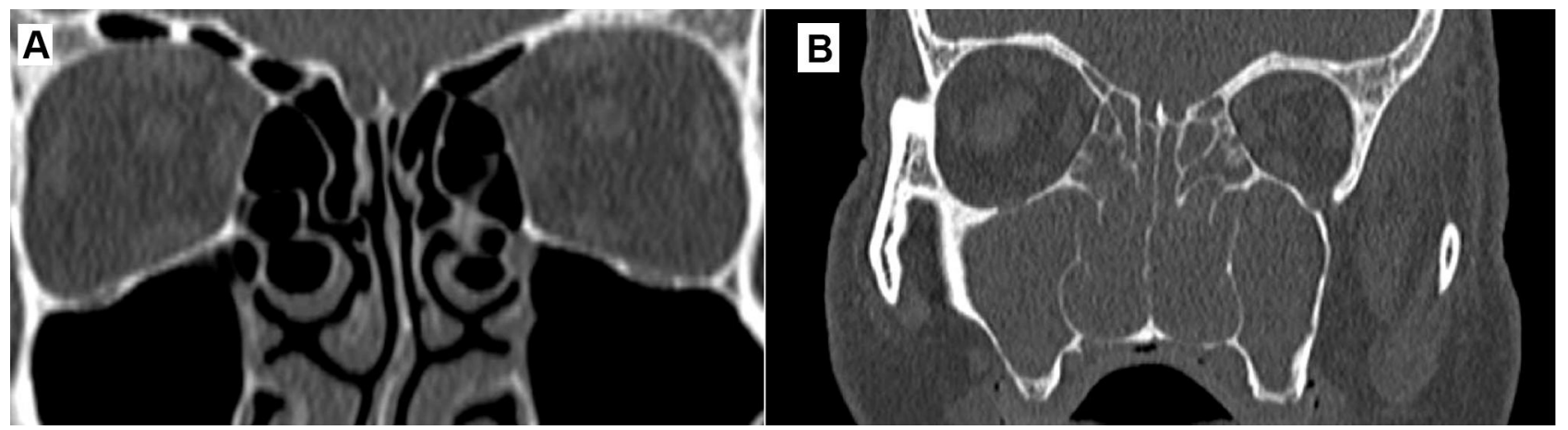

Figure 3 Comparison of ethmoid sinus CCAD (A) vs nonCCAD (B) features. Scale bar, $1 \mathrm{~cm}$ is equal to $5 \mathrm{~cm}$. Abbreviation: CCAD, central compartment atopic disease.

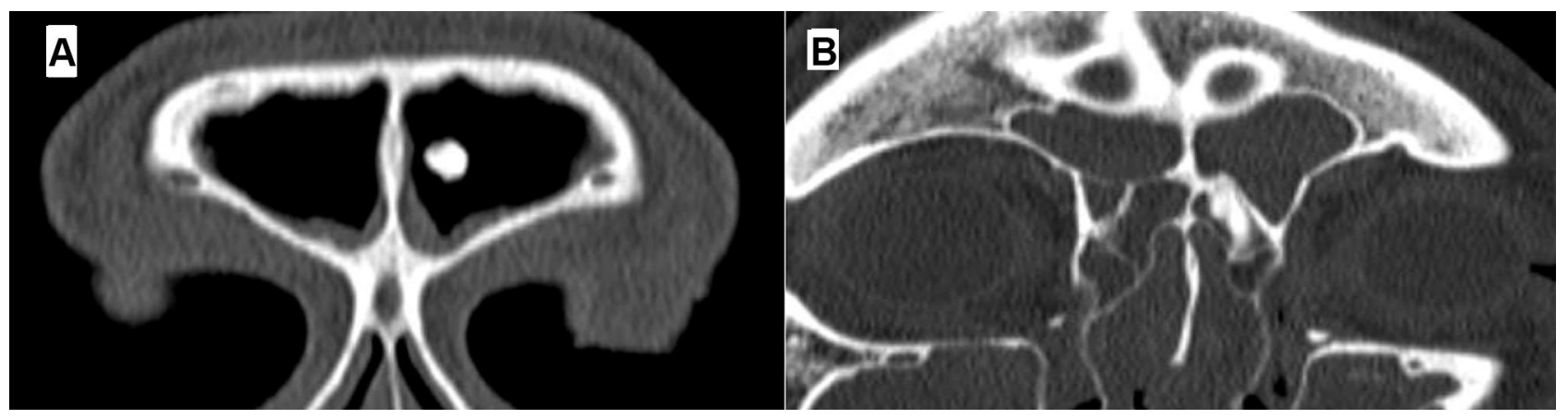

Figure 4 Comparison of frontal sinus CCAD (A) vs nonCCAD (B) features. Scale bar, $1 \mathrm{~cm}$ is equal to $5 \mathrm{~cm}$. Abbreviation: CCAD, central compartment atopic disease.

mean \pm SD or median (IQR) based on their normality distribution. Categorical data was presented as frequency (percent). Mann-Whitney test was used to determine the severity of symptoms score, LK score and LM score in allergy and CCAD. Pearson's chi-squared test was used to determine the association of middle turbinate edema and polypoid degeneration in allergy and CCAD. Statistical significance was set at $p<0.05$.

\section{Results}

\section{Participant Characteristics}

There were a total of 38 patients with CRSwNP recruited in this study; 19 patients with allergy and 19 patients without allergy. Table 1 shows the characteristics of the allergy and nonallergy populations. The mean age for the allergy group was $47.9+17.3$ years with a predominance of male $(68.4 \%)$ while for the non-allergy group, the mean age was 52.9+14.9 


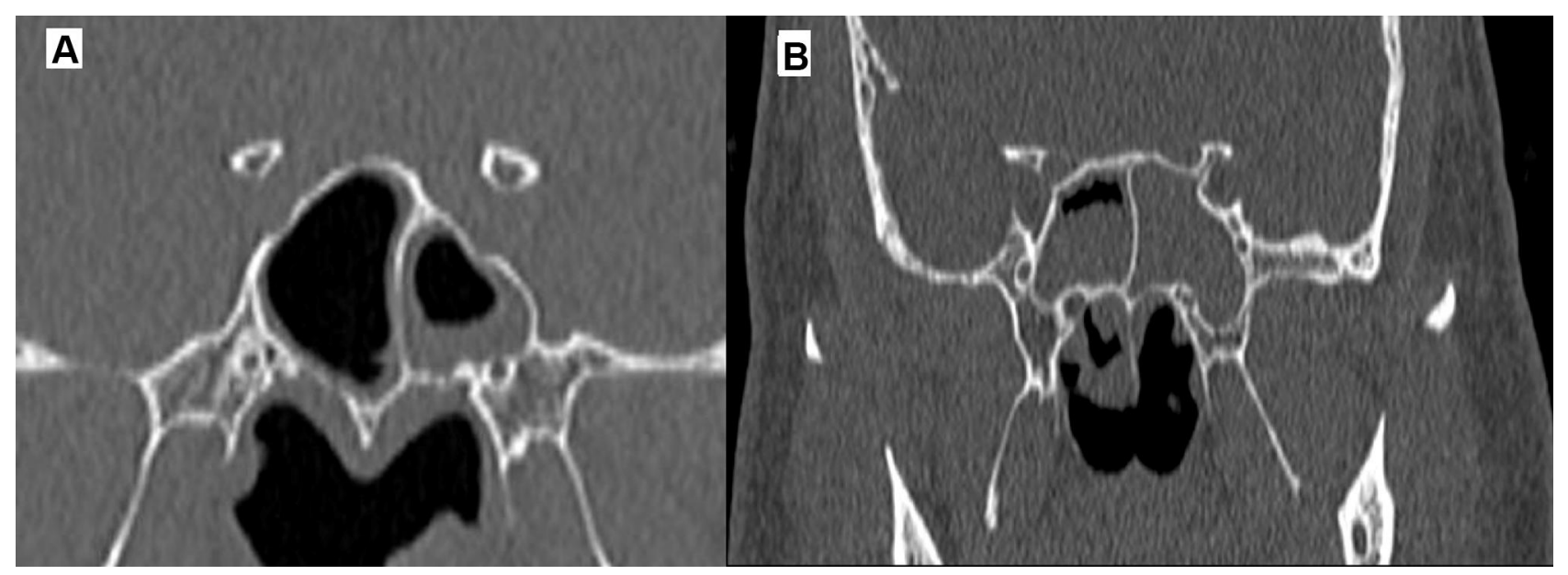

Figure 5 Comparison of sphenoid sinus CCAD (A) vs nonCCAD (B) features. Scale bar, I cm is equal to $5 \mathrm{~cm}$. Abbreviation: CCAD, central compartment atopic disease.

years and a predominance of female (52.6\%). All patients with allergy had symptoms suggestive of perennial rhinitis.

In the allergy group, we found $68.4 \%$ of patients were positive to both Dermatophagoides and Blomia tropicalis, and the rest were positive to Blomia tropicalis only. $26.3 \%$ of patients in the allergy group had bronchial asthma compared to $21.1 \%$ of patients in the non-allergy group. Only $60 \%$ of patients with bronchial asthma in the allergy group had allergic rhinitis and out of this, $67 \%$ had moderate and $33 \%$ had severe symptoms of need to blow nose and runny nose while all had moderate symptoms of sneezing. There were $21.1 \%$ of smokers in the allergy

Table I Characteristics of the Allergy and Nonallergy Populations

\begin{tabular}{|c|c|c|c|c|}
\hline Factors & $\begin{array}{l}\text { Allergy } \\
(n=19)\end{array}$ & $\begin{array}{l}\text { Nonallergy } \\
(n=19)\end{array}$ & Z stat & $p$-value \\
\hline Age $(\text { years })^{a}$ & $47.9 \pm 17.3$ & $52.9 \pm 14.9$ & -1.30 & 0.20 \\
\hline Gender (female) (\%) & 31.6 & 52.6 & -0.88 & 0.38 \\
\hline Asthma (\%) & 26.3 & 21.1 & -0.38 & 0.71 \\
\hline Smoking (\%) & 21.1 & 31.6 & -0.73 & 0.47 \\
\hline Symptoms score ${ }^{\mathrm{a}}$ & $1.37 \pm 0.60$ & $1.11 \pm 0.66$ & -1.25 & 0.21 \\
\hline Lund-Kennedy score ${ }^{a}$ & $5.58 \pm 2.71$ & $3.42 \pm 1.64$ & -2.45 & 0.01 \\
\hline Lund-ackay score $^{a}$ & $14.32 \pm 8.04$ & $8.53 \pm 6.24$ & -2.34 & 0.02 \\
\hline $\begin{array}{l}\text { Intranasal steroid use } \\
\text { (\%) }\end{array}$ & 100.0 & 100.0 & 0.00 & 1.00 \\
\hline Oral steroid use (\%) & 63.2 & 36.8 & -1.60 & 0.11 \\
\hline I course $(\%)$ & 0 & 36.8 & & \\
\hline 2 course $(\%)$ & 15.8 & 0 & & \\
\hline 3 course $(\%)$ & 26.3 & 0 & & \\
\hline 4 course $(\%)$ & 10.5 & 0 & & \\
\hline 5 course $(\%)$ & 5.3 & 0 & & \\
\hline 6 course $(\%)$ & 5.3 & 0 & & \\
\hline
\end{tabular}

Note: ${ }^{a}$ Mean SD. group and $31.6 \%$ in the non-allergy group. The use of intranasal steroid spray was $100 \%$ for both allergy and nonallergy groups. The use of oral steroid was higher in the allergy group (63.2\%) in comparison with the nonallergy group (36.8\%). Table 2 shows characteristics of the CCAD radiological pattern. There were a total of 16 patients that had CCAD features based on CTPNS with mean age of $49.4 \pm 16.9$ and a male predominance $(62.5 \%)$.

In the CCAD group, $100 \%$ of patients had allergy, $25 \%$ had bronchial asthma and $25 \%$ were smokers. The patients with bronchial asthma in the CCAD group all had history of allergic rhinitis with significant symptoms of need to blow nose (50\% with moderate and 50\% with severe symptoms), sneezing (50\% with mild and 50\% with moderate symptoms) and runny nose (50\% mild, $25 \%$ moderate and $25 \%$ with severe symptoms). None of these patients were documented to have aspirin or nonsteroidal anti-inflammatory drug hypersensitivity. All the patients had no allergic conjunctivitis, dermatitis, food or drug allergies. The use of intranasal steroid spray was $100 \%$ for both CCAD and the non-CCAD groups, while the use of oral steroid was higher in the CCAD group (68.8\%) in comparison with the nonCCAD group (36.4\%). 18.8\% of patients received two courses of oral prednisolone, $25 \%$ received three courses, $12.5 \%$ received four courses and another $6.25 \%$ received five and six courses, respectively in the CCAD group. Each course consisted of $30 \mathrm{mg}$ prednisolone daily given for two weeks to reduce the inflammation. In the nonCCAD group, $31.8 \%$ of patients received only one course of oral prednisolone and $4.6 \%$ received three courses of oral prednisolone. 
Table 2 Characteristics of the Central Compartment Atopic Disease Radiological Pattern

\begin{tabular}{|l|l|l|l|l|}
\hline Factors & $\begin{array}{l}\text { CCAD } \\
(\mathbf{n = 1 6 )}\end{array}$ & $\begin{array}{l}\text { Non-CCAD } \\
(\mathbf{n = 2 2 )}\end{array}$ & Z stat & p-value \\
\hline Allergy, \% & 100.0 & 13.6 & -5.19 & 0.00 \\
Age (years) & $49.4 \pm 16.9$ & $51.1 \pm 15.9$ & -0.30 & 0.77 \\
Gender (female) (\%) & 37.5 & 45.5 & -0.48 & 0.63 \\
Asthma (\%) & 25.0 & 22.7 & -0.16 & 0.87 \\
Smoking (\%) & 25.0 & 27.3 & -0.16 & 0.88 \\
Symptoms score & $1.44 \pm 0.63$ & $1.09 \pm 0.61$ & -1.71 & 0.09 \\
Lund- Kennedy $^{\mathrm{a}}$ & $6.00 \pm 2.71$ & $3.41 \pm 1.59$ & -2.93 & 0.03 \\
score & & & & \\
Lund-Mackay score & $14.63 \pm 8.12$ & $9.09 \pm 6.58$ & -2.27 & 0.02 \\
Intranasal steroid & 100.0 & 100.0 & 0.00 & 1.00 \\
use (\%) & & & & \\
Oral steroid use (\%) & 68.8 & 36.4 & -1.95 & 0.05 \\
I course (\%) & 0 & 31.8 & & \\
2 course (\%) & 18.8 & 0 & & \\
3 course (\%) & 25 & 4.6 & & \\
4 course (\%) & 12.5 & 0 & & \\
5 course (\%) & 6.25 & 0 & & \\
6 course (\%) & 6.25 & 0 & \\
\hline
\end{tabular}

Note: ${ }^{\mathrm{a}}$ Mean SD.

Abbreviation: CCAD, central compartment atopic disease.

\section{Symptoms Severity in Allergy and CCAD Groups}

The mean symptoms score in the allergy and non-allergy groups is shown in Table 1. The mean symptoms score in the CCAD and non-CCAD groups is shown in Table 2. The symptom of need to blow nose was significantly higher in the allergy group when compared to the non-allergy group. Allergy group was shown to have higher proportion of sneezing symptom, but the difference was not statistically significant while no difference was seen on runny nose symptom for both groups (Table 3). For the CCAD group, the symptoms of need to blow nose and sneezing showed higher incidence as compared to the non-CCAD group with no difference on symptom of runny nose.

\section{Endoscopic Scoring in Allergy and CCAD Groups}

There was a significant difference in the LK endoscopic scoring between both allergy and the nonallergy groups (Table 1). When CCAD group was compared to the nonCCAD group, there was a significant difference in LK endoscopic score (Table 2). Table 4 shows the middle turbinate characteristics of the allergy and nonallergy group. The allergy group had worse edema and polypoidal degeneration of the middle turbinates on both sides
Table 3 Individual Rhinologic Score, Percent Moderate Problem or More

\begin{tabular}{|l|l|l|l|l|}
\hline & $\begin{array}{l}\text { Allergy } \\
\text { (\%) }\end{array}$ & $\begin{array}{l}\text { Nonallergy } \\
\text { (\%) }\end{array}$ & Z stat & p-value \\
\hline $\begin{array}{l}\text { Need to blow } \\
\text { nose } \\
\begin{array}{l}\text { Sneezing } \\
\text { Runny nose }\end{array}\end{array}$ & 73.7 & 42.1 & -2.56 & 0.01 \\
\hline & 58.8 & 21.1 & -0.73 & 0.47 \\
& CCAD & NonCCAD & & \\
\hline $\begin{array}{l}\text { Need to blow } \\
\text { nose }\end{array}$ & 75.1 & 45.4 & -2.30 & 0.02 \\
Sneezing & 43.8 & 18.1 & -1.16 & 0.24 \\
Runny nose & 56.4 & 59.1 & -0.62 & 0.54 \\
\hline
\end{tabular}

Table 4 Middle Turbinate Characteristics of the Allergic and Nonallergic

\begin{tabular}{|l|l|l|l|}
\hline & $\begin{array}{l}\text { Allergic } \\
\text { (\%) }\end{array}$ & $\begin{array}{l}\text { Nonallergic } \\
\text { (\%) }\end{array}$ & $p$-value \\
\hline $\begin{array}{l}\text { Left Middle Turbinate } \\
\text { No edema } \\
\text { Edema or polypoidal } \\
\text { degeneration }\end{array}$ & 15.8 & 36.8 & 0.141 \\
\hline $\begin{array}{l}\text { Right Middle Turbinate } \\
\text { No edema } \\
\text { Edema or polypoidal } \\
\text { degeneration }\end{array}$ & 84.2 & 63.2 & \\
\hline
\end{tabular}

compared to the nonallergy group, but the difference was not significant. Table 5 shows the middle turbinate characteristics of the CCAD and nonCCAD. The middle turbinate changes showed the CCAD group had significantly worse edema and polypoidal degeneration on both sides compared to the nonCCAD group.

Table 5 Middle Turbinate Characteristics of the CCAD and NonCCAD

\begin{tabular}{|l|l|l|l|}
\hline & $\begin{array}{l}\text { CCAD } \\
\text { (\%) }\end{array}$ & $\begin{array}{l}\text { NonCCAD } \\
\text { (\%) }\end{array}$ & p-value \\
\hline $\begin{array}{l}\text { Left Middle Turbinate } \\
\text { No edema } \\
\begin{array}{l}\text { Edema or polypoidal } \\
\text { degeneration }\end{array}\end{array}$ & 6.3 & 40.9 & 0.017 \\
\hline $\begin{array}{l}\text { Right Middle Turbinate } \\
\text { No edema } \\
\text { Edema or polypoidal } \\
\text { degeneration }\end{array}$ & 93.8 & 59.1 & \\
\hline
\end{tabular}




\section{Lund-Mackay Scoring in Allergy and CCAD Groups}

There was a significant difference in LM CTPNS scoring between the allergy and the nonallergy groups (Table 1). A significant difference was also seen between the CCAD and the nonCCAD groups (Table 2) (Figures 2-5). Tables 1 and 2 show the correlation between clinical symptoms of CRSwNP with LK and LM scoring.

\section{Discussion}

In investigating the role of allergy in CRS patients, $\mathrm{Li}$ et $\mathrm{al}^{11}$ found $47 \%$ of their patients had allergy but the disease severity and recurrence rates were the same, irrespective of the allergy status. When the presence of allergy was related to the findings of CTPNS, Erbek et $\mathrm{al}^{12}$ and Peric et $\mathrm{al}^{13}$ found no association between allergy with both endoscopic findings and LM scores in their respective studies. Pearlman et al ${ }^{14}$ found there was $52 \%$ of allergy in their patients but no difference in the LM scores between the allergy and nonallergy groups. In another study, Banerji et $\mathrm{al}^{15}$ reported there was no difference in CTPNS severity score based on allergic profiles of their patients. Similarly, Tan et $\mathrm{al}^{16}$ demonstrated there was no difference between CTPNS LM severity and allergic status. Moreover, Basu et $\mathrm{al}^{17}$ and Brook et $\mathrm{al}^{18}$ showed that LM CTPNS severity in CRS patients did not correlate with symptom severity and allergen sensitization, respectively.

In contrast, the results of our study demonstrated an association between allergy and CRSwNP; the allergy group of patients had worse endoscopic and CTPNS scores in comparison to the nonallergy group. Our findings were consistent with the study done by Ramadan et $\mathrm{al}^{3}$ who found their patients with allergy had worse CTPNS scoring compared to those without allergy. Interestingly, Emanuel and Shah ${ }^{19}$ showed although the majority of CRS patients had allergic sensitization, it did not correlate with the severity of CTPNS scoring. In another study, Yacoub et $\mathrm{al}^{20}$ reported that atopy, clinical allergy, asthma and NSAIDS hypersensitivity could play a role in CRS. Krouse $^{21}$ found allergic sensitization influenced the severity of symptoms in CRS patients but not the severity of the CTPNS scoring. A recent study by Ho et $\mathrm{al}^{22}$ showed CRS patients with comorbid allergy had additional symptoms burden and they recommended every CRS patient be assessed for atopy to ensure proper treatment.

We believe the incongruity between our results with the others owing to the standardization of our patients with
CRSwNP sensitized to only house dust mite whereas other studies enrolled both CRSsNP and CRSwNP sensitized to all types of aeroallergens. Marcus et $\mathrm{al}^{23}$ supported this postulation by stating their observation that the broad phenotyping of CRSsNP and CRSwNP, most probably contributed to the substantially conflicting results. By standardizing the aeroallergen and the CRS phenotype, the clinical and radiological features could be better understood. Our study showed an association between CCAD and allergy in patients with CRSwNP and support a prior study by Hamizan et $\mathrm{al}^{1}$ which demonstrated a prevalence of the centrally limited disease defined by the CCAD classification system in their CRS patients with aeroallergen sensitization. DelGaudio et $\mathrm{al}^{10}$ demonstrated a strong association of CCAD with allergy and defined the early stage of CCAD with initial polypoidal changes of the middle turbinate and subsequently involvement of the superior turbinate and posterosuperior nasal septum edema. Further progress of the disease was defined by the involvement of the central sinus cavities with more severe cases of CCAD showed near-complete sinus opacification with medial to lateral direction involvement of the sinuses; the nonallergy group of CRS showed diffuse involvement of the sinuses without affecting the middle turbinate, superior turbinate or the nasal septum. ${ }^{10}$ Our study revealed that patients having CRSwNP with concomitant allergy experienced worse middle turbinate edema and polypoid degeneration.

At present, the management of CRSwNP is focused on managing the nasal polyps without a routine investigation of the allergy status. Skin prick test and serum specific IgE are not part of the standard investigations for chronic rhinosinusitis. In view of the impact of allergy on patients with CRSwNP, our approach needs to change. Besides the symptoms of allergy, the features of CCAD on CTPNS should be recognized as a sign of the possibility of a concomitant allergy in CRSwNP patients which needs to be investigated and confirmed. Most of the patients with CRSwNP are treated by intranasal corticosteroids, systemic corticosteroids, and macrolides (used as immunomodulators). Those who failed the optimal medical management and in recurrent cases, may require surgery. Patients with CRSwNP with positive allergy status may benefit from immunotherapy and avoid surgery. Studies have shown that patients with CRS and concomitant allergy have shown significant improvement of symptoms and quality of life when treated by immunotherapy compared to the conventional medical treatment. ${ }^{24,25}$ Moreover, there is potential immunomodulation in patients 
with CRS by the administration of long-term immunotherapy, thus, reducing their dependence on corticosteroids and avoiding its unwanted complications.

\section{Conclusions}

Allergy must be properly assessed in patients with CRSwNP as they may affect the clinical and radiological severity. When compared to the nonallergic type, the allergic phenotype has more polypoidal involvement of the middle turbinates, additional symptom burden of allergy and worse endoscopic and CTPNS scoring. Optimal treatment of allergy is essential for a better outcome.

\section{Ethics Approval and Informed Consent}

All procedures performed and data collected in this study adhered to the guidelines of the Declaration of Helsinki and the ethical standards of institutional ethics review committees. The Human Research Ethics Review Board of Universiti Sains Malaysia (JEPeM Code: USM/JEPeM/ 17,120,676) granted approval to conduct this research. Written consent was obtained from each patient.

\section{Author Contributions}

All authors contributed to data analysis, drafting or revising the article, have agreed on the journal to which the article will be submitted, gave final approval of the version to be published, and agree to be accountable for all aspects of the work.

\section{Funding}

There is no funding to report.

\section{Disclosure}

The authors report no conflicts of interest in this work.

\section{References}

1. Hamizan AW, Loftus PA, Alvarado R, et al. Allergic phenotype of chronic rhinosinusitis based on radiologic pattern of disease. Laryngoscope. 2018;128(9):2015-2021. doi:10.1002/lary.27180

2. Batra PS, Tong L, Citardi MJ. Analysis of comorbidities and objective parameters in refractory chronic rhinosinusitis. Laryngoscope. 2013;123(S7):S1-11. doi:10.1002/lary.24418

3. Ramadan HH, Fornelli R, Ortiz AO, et al. Correlation of allergy and severity of sinus disease. Am J Rhinol. 1999;13(5):345-347. doi:10.2500/105065899781367500

4. Van Zele T, Claeys S, Gevaert P, et al. Differentiation of chronic sinus diseases by measurement of inflammatory mediators. Allergy. 2006;61 (11):1280-1289. doi:10.1111/j.1398-9995.2006.01225.x

5. Bachert C, Pawankar R, Zhang L, et al. ICON: chronic rhinosinusitis. World Allergy Organ J. 2014;7:25. doi:10.1186/1939-4551-7-25
6. Fokkens WJ, Lund VJ, Mullol J, et al. EPOS 2012: European position paper on rhinosinusitis and nasal polyps 2012. A summary for otorhinolaryngologists. Rhinology. 2012;50(1):1-12. doi:10.4193/ Rhino50E2

7. Yeoh SM, Kuo IC, Wang DY, et al. Sensitization profiles of Malaysian and Singaporean subjects to allergens from Dermatophagoides pteronyssinus and Blomia tropicalis. Int Arch Allergy Immunol. 2003;132(3):215-220. doi:10.1159/000074302

8. Lund VJ, Kennedy DW. Quantification for staging sinusitis. The Staging and Therapy Group. Ann Otol Rhinol Laryngol. 1995;104:17-21. doi:10.1177/000348949510410s02

9. Lund VJ, Mackay IS. Staging in rhinosinusitis. Rhinology. 1993;31 (4):183-184.

10. DelGaudio JM, Loftus PA, Hamizan AW, et al. Central compartment atopic disease. Am J Rhinol Allergy. 2017;31(4):228-234. doi:10. 2500/ajra.2017.31.4443

11. Li QC, Cheng KJ, Wang F, et al. Role of atopy in chronic rhinosinusitis with nasal polyps: does an atopic condition affect the severity and recurrence of disease? J Laryngol Otol. 2016;130(7):640-644. doi: $10.1017 /$ S0022215116008112

12. Erbek SS, Erbek S, Topal O, et al. The role of allergy in the severity of nasal polyposis. Am J Rhinol. 2007;21(6):686-690. doi:10.2500/ ajr.2007.21.3062

13. Peric A, Vojvodic D, Vukomanovic-Durdevid B. Influence of allergy on clinical, immunological and histological characteristics of nasal polyposis. B-ENT. 2012;8(1):25-32.

14. Pearlman AN, Chandra RK, Chang D, et al. Relationships between severity of chronic rhinosinusitis and nasal polyposis, asthma, and atopy. Am J Rhinol Allergy. 2009;23(2):145-148. doi:10.2500/ajra.2009.23.3284

15. Banerji A, Piccirillo JF, Thawley SE, et al. Chronic rhinosinusitis patients with polyps or polypoid mucosa have a greater burden of illness. Am J Rhinol. 2007;21(1):19-26. doi:10.2500/ajr.2007.21.2979

16. Tan BK, Zirkle W, Chandra RK, et al. Atopic profile of patients failing medical therapy for chronic rhinosinusitis. Int Forum Allergy Rhinol. 2011;1(2):88-94. doi:10.1002/alr.20025

17. Basu S, Georgalas C, Kumar BN, et al. Correlation between symptoms and radiological findings in patients with chronic rhinosinusitis: an evaluation study using the Sinonasal Assessment Questionnaire and Lund-Mackay grading system. Eur Arch Otorhinolaryngol. 2005;262(9):751-754. doi:10.1007/s00405-004-0891-0

18. Brook CD, Kuperstock JE, Rubin SJ, et al. The association of allergic sensitization with radiographic sinus opacification. Am J Rhinol Allergy. 2017;31(1):12-15. doi:10.2500/ajra.2017.31.4394

19. Emanuel IA, Shah SB. Chronic rhinosinusitis: allergy and sinus computed tomography relationships. Otolaryngol Head Neck Surg. 2000;123(6):687-691. doi:10.1067/mhn.2000.110961

20. Yacoub MR, Trimarchi M, Cremona G, et al. Are atopy and eosinophilic bronchial inflammation associated with relapsing forms of chronic rhinosinusitis with nasal polyps? Clin Mol Allergy. 2015;13 (1):23. doi:10.1186/s12948-015-0026-8

21. Krouse JH. Computed tomography stage, allergy testing, and quality of life in patients with sinusitis. Otolaryngol Head Neck Surg. 2000;123(4):389-392. doi:10.1067/mhn.2000.109476

22. Ho J, Alvarado R, Rimmer J, et al. Atopy in chronic rhinosinusitis: impact on quality of life outcomes. Int Forum Allergy Rhinol. 2019;9 (5):501-507. doi:10.1002/alr.22272

23. Marcus S, John M, DelGaudio JM, et al. Chronic rhinosinusitis: does allergy play a role? Med Sci (Basel). 2019;7(2):30. doi:10.3390/ medsci7020030

24. Asakura K, Kojima T, Shirasaki H, et al. Evaluation of the effects of antigen specific immunotherapy on chronic sinusitis in children with allergy. Auris Nasus Larynx. 1990;17(1):33-38. doi:10.1016/s03858146(12)80018-6

25. Li N, Peters AT. Chronic rhinosinusitis management beyond intranasal steroids and saline solution irrigations. Allergy Asthma Proc. 2015;36(5):339-343. doi:10.2500/aap.2015.36.3866. 


\section{Publish your work in this journal}

The Journal of Asthma and Allergy is an international, peer-reviewed open-access journal publishing original research, reports, editorials and commentaries on the following topics: Asthma; Pulmonary physiology; Asthma related clinical health; Clinical immunology and the immunological basis of disease; Pharmacological interventions and

Submit your manuscript here: https://www.dovepress.com/journal-of-asthma-and-allergy-journal new therapies. The manuscript management system is completely online and includes a very quick and fair peer-review system, which is all easy to use. Visit http://www.dovepress.com/testimonials.php to read real quotes from published authors. 